\title{
Levantamento da família Polygonaceae no estado da Bahia, Brasil: espécies do semi-árido*
}

\author{
Efigênia de Melo ${ }^{1}$
}

RESUMO

Foi feito o levantamento das espécies da família Polygonaceae distribuídas na zona semiárida do estado da Bahia. A família está representada na área por 5 gêneros com 21 (vinte e uma) espécies, das quais, o maior número pertence ao gênero Coccoloba (11): C. alagoensis, C. alnifolia, C. brasiliensis, C. bullata, C. confusa, C. fastigiata, C. mosenii, C. ochreolata, C. scandens, C. schwakeana e C. warmingii; seguido por Polygonum (5): P. acuminatum, P. ferrugineum, $P$. hispidum, $P$. hydropiperoides e $P$. punctatum; Ruprechtia (3): $R$. apetala, $R$. laxiflora e R. ramiflora; Rumex (1): R. crispus e Triplaris (1): T. gardneriana. São apresentadas chaves de identificação, descrições sucintas e ilustrações para a maioria das espécies.

Palavras-chave: Polygonaceae, Taxonomia, Florística, Bahia
\end{abstract}

ABSTRACT
This research is a survey of the Polygonaceae species distributed in semi-arid zone of state of the Bahia. In that area the family is represented by the following genera with their respective species: Coccoloba (11): C. alagoensis, C. alnifolia, C. brasiliensis, C. bullata, C. confusa, C. fastigiata, C. mosenii, C. ochreolata, C. scandens, C. schwakeana and C. warmingii; Polygonum (5): P. acuminatum, P. ferrugineum, P. hispidum, P. hydropiperoides and P. punctatum; Ruprechtia (3): R. apetala, R. laxiflora and R. ramiflora; Rumex (1) R. crispus and Triplaris (1) T. gardneriana. Key to the genera and species, descriptions and illustrations are presented for the majority of the species studied.

Keywords: Polygonaceae, Taxonomy, floristic, Bahia

\section{INTRODUÇÃO}

A localização da área "core" da vegetação de caatinga está ligada ao domínio morfo-climático semi-árido. Pode-se considerar, de modo geral, como semi-árida toda a área com índice pluviométrico inferior a $800 \mathrm{~mm} /$ anuais (Aiouad 1986). No estado da Bahia, essa área ocupa cerca de 50\% do território, distribuindo-se na porção norte e centro-sul do estado (Noblick 1991; fig.1). Os diferentes tipos de caatinga não se distribuem homogeneamente nessa área. De acordo com a atual classificação de VELOSO et al. (1991) a caatinga apresenta-se como uma mistura complexa de fisionomias, agrupadas em 4 tipos básicos: savana-estépica florestada, savanaestépica arborizada, savana-estépica parque e savana-estépica gramíneo-lenhosa. As condições ecológicas mais típicas do semi-árido são encontradas nas depressões interplanálticas de grande extensão encaixadas entre os maciços mais antigos (Aiouad 1986). Nestes locais, geralmente de baixas altitudes, as deficiências hídricas refletem na vegetação um caráter xerófilo e decíduo típico da caatinga. Dentro do domínio do semi-árido estão encravados outros tipos de vegetação que não são caatingas, tais como, os campos rupestres da Chapada Diamantina, os cerrados

\footnotetext{
"Trabalho apresentado na 4a.Reunião Especial da SBPC ("Semi-árido no terceiro milênio, ainda um desafio").

${ }^{1}$ Prof. Assistente, Universidade Estadual de Feira de Santana, Departamento de Ciências Biológicas, Km3, BR-116 N, Campus Universitário, Feira de Santana, Bahia, Brasil, CEP 44.031-460. Fone: (075) 224-8236. FAX (075) 224-1926, Emailherbario@uefs.br
} 
disjuntos, principalmente em áreas transicionais, as florestas estacionais e, manchas de mata atlântica também nas transições.

Em termos florísticos, a caatinga mostra fortes ligações com a floresta estacional (Harley 1995). Estas ocorrem em disjunções principalmente nas áreas transicionais entre a mata atlântica e a caatinga, a leste, entre a caatinga e o cerrado, a oeste ou entre a caatinga e os campos de altitudes (cerrados e campos rupestres) na porção central do estado (Noblick 1991). Nas regiões montanas, a altitudes entre 700 e $2000 \mathrm{~m}$, a caatinga é substituída pelos cerrados e campos rupestres, verdadeiros refúgios ecológicos em meio ao semi-árido, predominantes sobre os maciços montanhosos da Chapada Diamantina (Noblick 1991).

A família Polygonaceae possui cerca 30 gêneros e aproximadamente 750 espécies distribuídas principalmente nas regiões temperadas do hemisfério norte. A maioria das espécies é cosmopolita. Algumas espécies são cultivadas para ornamentação (Triplaris, Ruprechtia, Antigonum, Coccoloba), ou utilizadas como fontes forrageiras e medicinais por exemplo Rumex, Polygonum e Fagopyrum (Heywood 1978). Além disso, as espécies arbóreo-arbustivas representam importantes componentes fitogeográficos principalmente por ocorrerem em densas populações (Rizzini 1978, 1986).

Poucos trabalhos têm feito referência à família no estado da Bahia (Harley \& Mayo 1980), (Harley \& Simmons, 1986), (Rizzini 1986), (Harley et al. 1995), (Melo 1996).

\section{MATERIAL E MÉTODOS}

Foram analisadas amostras da coleção dos seguintes herbários: ALCB, CEN, CEPEC, HRB, HUEFS, IBGE, IPA, K, MBM, MG, PEUFR, R, RB, SP, SPF, UB e UPCB (siglas de acordo com o Index Herbariorum, HOLMGREEN et al. 1990).

As coletas provenientes de todo o estado, principalmente da zona semi-árida foram depositadas no Herbário da Universidade Estadual de Feira de Santana (HUEFS).

Foram consideradas pertencentes a zona semi-árida toda a amostra que se enquadrasse nos seguintes critérios: ser procedente de um município, parcial ou totalmente incluído no semi-árido de acordo com o CEI (1994); ter sido coletada na região fitoecológica da caatinga do estado da Bahia ou ter sido coletada dentro da área do polígono das secas, na Bahia.

O material citado corresponde unicamente às amostras provenientes da zona semi-árida do estado da Bahia, depositadas nos diversos herbários consultados.

A nomenclatura para a classificação dos frutos está de acordo com SPJUT, 1994.

As espécies foram ilustradas por Ivan de Castro.

\section{RESULTADOS E DISCUSSÃO}

A família Polygonaceae está representada no semi-árido baiano por 21 espécies distribuídas em 5 gêneros: Coccoloba, Polygonum, Rumex, Ruprechtia e Triplaris, dos quais Coccoloba é o mais representativo com 11 espécies, seguido por Polygonum com 5, Ruprechtia com 3, Rumex e Triplaris com uma espécie. 


\section{CHAVE PARA IDENTIFICAÇÃO DOS GÊNEROS}

1 Ervas ou subarbustos, fruto diclésio

2 Perianto frutífero livre, com intumescimento dorsal sobre as alas Rumex

2' Perianto frutífero aderido, sem intumescimento dorsal Polygonum

1 ' Arbustos, árvores ou lianas, frutos de outros tipos

3 Fruto pseudosâmara

4 Tubo do perianto frutífero basalmente soldado, fruto incluso no tubo Triplaris

4' Tubo do perianto frutífero livre ou soldado até $1 / 3$, fruto total ou parcialmente excluso

3' Fruto acrossarco

Coccoloba P. Br. ex L., Syst. Nat. ed. 10.2:1367, 1759.

Arbusto escandente, árvores ou lianas, até 20 $\mathrm{m}$ alt., monóicos ou dióicos. Ramos glabros ou pubescentes, lenticelas oblongas, elípticas ou arredondadas. Folhas membranáceas ou coreáceas, glabras ou pubescentes, muito variáveis em tamanho e formato, freqüentemente com glândulas punctiformes; ócreas membranáceas ou coreáceas, base persistente ou totalmente caduca; pecíolo cilíndrico, achatado ou canaliculado. Inflorescências racemosas, raramente paniculadas. Flores
Ruprechtia

Coccoloba

\section{CHAVE PARA IDENTIFICAÇÃO DAS ESPÉCIES DO GÊNERO COCCOLOBA}

Folhas pubescentes em ambas as faces 6. C. fastigiata

1' Folhas glabras, se pubescentes, somente na face abaxial

2 Pecíolo inserido na base ou acima da ócrea

3 Folhas menores que $5 \mathrm{~cm}$. 4. C. bullata

3' Folhas maiores que $5 \mathrm{~cm}$

4' Folhas ovadas ou elípticas

5. C. confusa

4'Folhas obovadas

5 Folhas obovado-lanceoladas

5' Folhas obovado-orbiculares

6 Ápice curto-acuminado, margem revoluta, fruto com bordos fusionados

2. C. alnifolia

6‘ Ápice obtuso ou arredondado, margem plana, frutos com bordos livres

10. C. schwackeana

2' Pecíolo inserido abaixo da base da ócrea

7 Folhas lanceoladas ou elípticas, base aguda ou atenuada

8 Arbusto. Folhas elípticas

1. C. alagoensis

$8^{\prime}$ Arbusto escandente. Folhas lanceoladas

7. C. mosenii

7 ' Folhas oblongas, base cordada, subcordada ou arredondada

9 Ócreas e ocréolas muito desenvolvidas

8. C. ochreolata

9' Ócreas e ocréolas pouco desenvolvidas

10 Arbusto ereto

3. C. brasiliensis

10' Arbusto escandente

9. C. scandens 


\section{Coccoloba alagoensis Wedd., Ann. Sci. Nat. III. 13:260, 1849.}

(Fig. 2-4)

Arbusto ereto, densamente ramificado, com até $3,0 \mathrm{~m}$ alt.; ramos com casca acinzentada, lenticelas oblongas, alvas, internós maciços. Folhas elípticas a oblongas, 5-10 x 3$6 \mathrm{~cm}$, ápice agudo ou obtuso, base aguda, raro subarredondada, margem plana, membranáceas a sub-coreáceas, glabras, tricomas remanescentes nas axilas das nervuras da face abaxial, glândulas punctiformes visíveis na face abaxial, nervação impressa em ambas as faces; ócrea 0,5-1cm, membranácea, glabra, com pontos glandulosos; pecíolo achatado $0,5-1,5 \mathrm{~cm}$, inserido abaixo da base da ócrea. Racemos eretos, $4-10 \mathrm{~cm}$, raque glabra, estriada. Flores 1-1,5mm. Fruto oval, 0,5-1cm, perianto membrano-paleáceo, estriado, ápice agudo, com bordos livres.

Ocorre nos estados de Mato Grosso, Alagoas, Bahia e Minas Gerais (Rizzini 1986). Habita a floresta atlântica, amazônica e matas ciliares (Rizzini 1986). Na zona semi-árida foi encontrada nas margens do rio São Francisco. Espécie próxima a C. ovata, diferindo basicamente por apresentar folhas e frutos relativamente menores. Floresce e frutifica de janeiro a junho.

Material selecionado:

Bahia: Barra, 25/II/1997, L. P. de Queiroz 4847 (HUEFS); Santo Inácio, 26/II/1977, R. M. Harley 19082 (CEPEC, HRB, K, MBM); Xique-Xique, 05/IV/76, G. Davidsen 12011 (SP); Idem, 23/VI/96, A. M. Giulietti PCD 2988 (ALCB, HUEFS, SPF).

\section{Coccoloba alnifolia Casar., Nov. Stirp. Bras. 8:71, 1844.}

(Fig. 5-6)

Arbusto a árvore de 2-20m de alt.; ramos com casca fissurada, lenticelas oblongas a elípticas, alvas, internós maciços. Folhas obovadas a sub-arredondadas, lâmina 6-15 x 4-14cm, ápice curto-acuminado a arredondado, base obtusa, arredondada a subcordada, margem revoluta, coreácea, face adaxial glabra, abaxial com tricomas remanescentes nas axilas e ao longo das nervuras, glândulas punctiformes visíveis na face abaxial, nervação marcada na face adaxial e proeminente na abaxial; ócrea 1-2cm, coreácea, glabrescente, base persistente; pecíolo $0,5-1,5 \mathrm{~cm}$, achatado dorsalmente, inserido acima da base da ócrea. Racemos densifloros, eretos, $10-30 \mathrm{~cm}$, raque estriada, pubérula. Flores 1-2mm. Fruto oval, 3-5mm, ápice agudo, bordos aderidos.

Ocorre na restinga e mata atlântica, nos estados de Pernambuco, Bahia, Minas Gerais e Rio de Janeiro (Rizzini 1986). A planta pode atingir porte arbóreo de até $20 \mathrm{~m}$ de altura. $\mathrm{Na}$ área de estudo foi encontrada nas matas estacionais, transição entre a mata atlântica e a caatinga e nas margens dos rios, formando densas populações arbustivas na planície arenosa do rio Paraguaçu e outros rios das bordas da Chapada Diamantina.

\section{Material selecionado:}

Bahia: Iaçu, 26/II/1983, G. C. P. Pinto 153 (HRB); Itaberaba, 04/VI/1995, F. França et al. 1217 (HUEFS); Lençóis, Remanso/ Marimbus, 29/I/1997, M. L. Guedes et al. PCD 4628 (ALCB, HUEFS).

\section{Coccoloba brasiliensis Nees \& Mart., Nov. Act. Acad. Nat. Cur. 11:30, 1823.}

(Fig. 7-8)

Arbusto ereto até $3 \mathrm{~m}$ alt.; ramos com casca fissurada, lenticelas elípticas, marrons, internós maciços. Folhas oblongas, 4-8 x 3-5cm, ápice obtuso a arredondado, base obtusa a subcordada, margem revoluta, coreáceas, glabras, glândulas punctiformes visíveis na face abaxial, nervação inconspícua na face adaxial, proeminente na abaxial; ócrea ca. $5 \mathrm{~mm}$, coreácea, glabra, com pontos glandulosos; pecíolo canaliculado $0,5-1,5 \mathrm{~cm}$, inserido abaixo da base da ócrea. Racemos eretos, $8-10 \mathrm{~cm}$, raque glabra, estriada. Flores $1-2 \mathrm{~mm}$. Fruto 
oval, 4-6mm, ápice agudo, bordos aderidos.

Ocorre nos campos e cerrados, nos estados de Mato Grosso, Bahia e Minas Gerais (Rizzini 1986). Na área de estudo foi encontrada na região de transição entre a mata estacional e a caatinga. Cresce formando densas populações arbustivas nas porções mais baixas da Chapada Diamantina.

Material selecionado:

Bahia: Barra da Estiva/Ibicoara, 28/I/ 1974, R. M. Harley 15562, 15563 (CEPEC, IPA); Barra da Estiva/Jussiape, 22/III/1980, R. M. Harley et al. 20791 (CEPEC); Rio de Contas, 4/II/1997, B. Stannard et al. PCD 5069 (ALCB, HUEFS); Idem, 2/II/1997, E. Saar et al. PCD 4891 (ALCB, HUEFS); Seabra, 20/III/1980, J. E. M. Brazão 171 (CEPEC). Vitória da Conquista, Melo, E. \& França, F. n (HUEFS).

\section{Coccoloba bullata How., Brittonia 44:365, 1992.}

Arbusto escandente; ramos enegrecidos hirsuto-ferrugíneo; casca fissurada, internós maciços. Folhas oblongo-lanceoladas, 4-4,5 x $2 \mathrm{~cm}$, ápice curto-acuminado, base cordada, coreácea, bulada entre as nervuras, face abaxial densamente hirsuto-pubescente, sem glândulas visíveis, nervação inconspícua na face adaxial, proeminente na abaxial; ócrea espatácea, ca. 5mm, coreácea; pecíolo 3-6mm, inserido acima da metade da ócrea. Racemos eretos, 5-6cm, raque pubérula, estriada. Fruto não observado.

Essa espécie é conhecida pelo seu typus, proveniente da mata de cipó, transição entre a mata atlântica e a caatinga. Endêmica da Bahia (Howard 1992).

Material selecionado:

Bahia: Maracás, 14/II/1979, L. A. Mattos Silva et al. 234 (isótipo CEPEC!)

\section{Coccoloba confusa How., Journ. Arn. arb. 41(4):223, 1960.}

(Fig. 9-11)

Arbusto escandente a liana; ramos com casca fissurada, acinzentada, lenticelas elípticas, alvas, internós maciços. Folhas elípticas, raramente ovado-lanceoladas, 4-9 x $3-5 \mathrm{~cm}$, ápice agudo, base cuneada, raro obtusa, margem revoluta, membrano-coreáceas, glabras, glândulas punctiformes visíveis na face abaxial, nervação finamente marcada em ambas as faces; ócrea $0,5-1 \mathrm{~cm}$, coreácea, glabra, pecíolo achatado $0,5-1,5 \mathrm{~cm}$, inserido pouco acima da base da ócrea. Racemos pêndulos delicados, $8-10 \mathrm{~cm}$, raque glabra, estriada. Fruto elíptico $0,5-1 \mathrm{~cm}$, ápice e base agudos, lobos aderidos.

Ocorre nas matas e restingas nos estados do amazonas, Pará, Rio de Janeiro, São Paulo e Minas Gerais (Rizzini 1978). Na zona semiárida foi coletada na mata estacional das encostas das serras, na região transicional entre a mata atlântica e a caatinga.

\section{Material selecionado:}

Bahia: Feira de Santana, 28/I/1993, L. P. de Queiroz 3046 (HUEFS, SPF)

\section{Coccoloba fastigiata Meisn., Fl. Bras. 5(1):34, 1855.}

(fig. 12-14)

Arbusto escandente; ramos cilíndricos, estriados, ápices tomentosos, internós maciços; lenticelas esparsas, arredondadas e elípticas, alvas. Folhas lanceoladas a oval-lanceoladas, 5,5-8 x 3,5-4,5cm, ápice agudo a curtoacuminado, base arredondada a subcordada, margem revoluta, coreácea, nervação imersa na face adaxial e proeminente na abaxial, densamente pubescente em ambas as faces; ócrea tubuloso-acuminada, coreácea, $0,5-1 \mathrm{~cm}$, densamente pubescente; pecíolo $0,5-2 \mathrm{~cm}$, ferrugíneo-tomentoso, inserido acima da base da ócrea. Racemos eretos $5-10 \mathrm{~cm}$. Flor 2$3 \mathrm{~mm}$. Fruto oval, $0,5-1 \mathrm{~cm}$, lobos aderidos.

C. fastigiata é citada para as restingas e mata atlântica dos estados do Rio de Janeiro e São Paulo (Rizzini 1986). Na área estudada, foi coletada uma amostra proveniente da floresta estacional, transição entre a caatinga e o cerrado.

Material selecionado:

Bahia: Caetité, Chapada Diamantina, 18/ 
V/1983, G. Hatschbach 46566 (HUEFS, MBM).

7. Coccoloba mosenii Lind., Bot. Jahrb. 13:173, 1890.

(Fig.15-17)

Arbusto escandente a liana; ramos cilíndricos estriados, internós maciços, lenticelas redondas a elíptica, alvas. Folhas lanceoladas, 9-19 x 2,5-6cm, ápice atenuado, base aguda a obtusa, margem revoluta, membranácea, nervação plana na face adaxial, abaxial proeminente; ócrea tubulosoacuminada, membranácea, $0,5-1 \mathrm{~cm}$, caduca; pecíolo $1-2 \mathrm{~cm}$, glabro, inserido abaixo da base da ócrea. Racemos 5-16cm. Flor 2-3mm. Fruto oval, ca. $1 \mathrm{~cm}$, lobos aderidos.

Espécie típica da mata atlântica dos estados de São Paulo e Rio de Janeiro (Howard 1960). Na zona semi-árida ocorre em relictos de mata atlântica nos ápices da Serra da Jibóia.

\section{Material selecionado:}

Bahia: Castro Alves, 27/V/1987, L. P. de Queiroz et al. 1564 (HUEFS); Santa Terezinha, 08/II/1997, F. França et al. 2098 (HUEFS).

8. Coccoloba ochreolata Wedd., Ann. Sci. Nat. III. 13:259, 1849.

(Fig. 18-20)

Arbusto escandente ou liana; ramos com casca acinzentada, lenticelas verrucosas, obscuras, internós maciços. Folhas ovais a oblongas, 6-14 x 3,5-10cm, ápice agudo ou obtuso, base arredondada, subcordada a cordada, margem revoluta, membranocoreáceas, glabras, glândulas punctiformes visíveis na face abaxial, nervação impressa em ambas as faces; ócrea $0,5-1,0 \mathrm{~cm}$, coreácea, glabra; pecíolo cilíndrico, estriado, $0,5-2 \mathrm{~cm}$, inserido abaixo da base da ócrea. Racemos pêndulos, $8-12 \mathrm{~cm}$, raque glabra, estriada. Flores $2-3 \mathrm{~mm}$. Fruto oval, $0,5-1 \mathrm{~cm}$, ápice agudo, bordos aderidos.

C. ochreolata é amplamente distribuída nos estados do Pará, Alagoas, Bahia, Espírito
Santo, e Rio de Janeiro (Rizzini 1978). Habita a caatinga, restinga, e florestas atlântica e amazônica (Howard 1960). No semi-árido foi coletada na vegetação de mata atlântica da Serra da Jibóia e nas áreas de caatinga nas bordas da Chapada Diamantina, nos municípios de Lençóis e Jacobina.

\section{Material selecionado:}

Bahia: Castro Alves, 13/XI/1994, F. França et al. 1086 (HUEFS); Idem, 25/VIII/ 1996, E. Melo et al. 1695 (HUEFS); Jacobina, 21/II/1993, A. Amorim et al. 999 (CEPEC); Idem, 30/III/96, R. M. Harley et al. PCD 2654 (ALCB, HUEFS); Idem, 6/IV/96, M. L. Guedes et al. PCD 2861 (ALCB, HUEFS, SPF); Idem, 4/IV/1996, R.M. Harley et al. PCD 2826 (ALCB, HUEFS, SPF); Idem, 2/ IV/1996, E. Woodgyer et al. PCD 2769 (ALCB, HUEFS, SPF); Lençóis, 30/I/1997, E. Saar et al. PCD 4728 (ALCB, HUEFS) .

\section{Coccoloba scandens Casar., Nov. Stirp. Bras. 8:70, 1844.}

(fig. 21-22)

Arbusto escandente a liana; ramos estriados, glabros, lenticelas arredondadas a elípticas, alvas e robustas. Folhas elípticas a oblongo-lanceoladas até ovais; lâmina 5-8 x 4$6 \mathrm{~cm}$, ápice agudo ou curto-acuminado, base aguda ou obtusa raramente subcordada, margem revoluta, coreácea, glabra a pubérula na face abaxial, glândulas punctiformes visíveis na face abaxial; ócrea caduca $0,5-1 \mathrm{~cm}$; pecíolo $0,5-1 \mathrm{~cm}$. Flores $1-2 \mathrm{~mm}$. Fruto arredondado, glabro, $0,8-1 \mathrm{~cm}$, bordos aderidos.

Espécie distribuída nos estados de Goiás, Minas Gerais, Pernambuco e Rio de Janeiro (Rizzini 1986). Ocorre nas matas ciliares em forma de cipós e nos cerrados, próximo aos rios, sob a forma de arbustos escandentes. $\mathrm{Na}$ área de estudo foi coletada nas encostas da Chapada Diamantina, no município de Lençóis.

Material selecionado:

Bahia: Lençóis, E. Melo et al. PCD 1700 (ALCB, HUEFS) 
10. Coccoloba schwackeana Lind., Bot. Jahrb. 13:200, 1890.

(fig. 23-24)

Arbusto ereto, até $4 \mathrm{~m}$ alt.; ramos com casca acinzentada, lenticelas arredondadas alvas, internós maciços. Folhas obovadoorbiculares a oblongas, 3,5-8 x 2,5-5,5cm, ápice arredondado, abrupto-acuminado ou obtuso, base cordada, subcordada a arredondada, margem plana, diminuto-crenada, coreáceas, glabras, tricomas remanescentes na nervura principal da face abaxial, glândulas punctiformes diminutas na face abaxial, nervação impressa em ambas as faces; ócrea 3-5mm, coreácea, pubescente; pecíolo cilíndrico, torcido, 3-5mm, inserido acima da base da ócrea. Racemos filiformes patentes, $5-10 \mathrm{~cm}$, raque glabra, estriada. Flores $1-2 \mathrm{~mm}$. Fruto redondo, 4-5mm, ápice obtuso, lobos livres.

C. schwackeana ocorre no Rio de Janeiro e Bahia (Rizzini 1986). Espécie bastante representativa da zona semi-árida, ocorrendo nas formações típicas de caatingas arbóreas, nas encostas serranas. Muito frequiente nas bordas da Serra Geral (Aracatu, Caetité e Ituaçu), na região de influência dos rios Paraguaçu e São Francisco e, na orla externa das matas estacionais da base dos Inselbergs, na região de Milagres. Cresce na forma de arbustos ou árvores com ramos escandentes ou não.

\section{Material selecionado:}

Bahia: Aracatu, 27/III/1984, C. B. de A. Bohrer 13 (ALCB, HUEFS); Boquira, 20/III/ 1984, H. P. Bautista \& O.A. Salgado 853 (ALCB, CEPEC, HRB, RB, UPCB); Caetité, 27/XI/1992, M. L. Guedes 2656 (ALCB); Itatim, 29/VI/1996, E. Melo et al.1639 (HUEFS); Idem, 14/XII/1996, E. Melo et al. 1894 (HUEFS); Idem, 29/IX/1996, F. França et al. 1860 (HUEFS); Ituaçu, 27/XI/1988, Idem, Morro da Mangabeira, 22/XII/1983, E. P. Gouveia 54/83 (ALCB); Milagres, 15/IV/ 1995, E. Melo \& F. França 1200 (HUEFS).

\section{Coccoloba warmingii Meisn., in Warm., Symb.: 128, 1870.}

(Fig. 25)

Arbusto a árvore até $10 \mathrm{~m}$ alt.; ramos com casca estriada fissurada, lenticelas oblongas a elípticas, marrons, internós maciços. Folhas obovado-lanceoladas, 8-11 x 6-8cm, ápice arredondado a curto-acuminado, raro emarginado, base truncada, arredondada, raro subcordada, margem ondulada, nervação proeminente na face abaxial, coreáceas, glabras, freqüentemente discolores; ócrea ca. $1 \mathrm{~cm}$, coreácea, estrigosa; pecíolo cilíndrico, 1$2 \mathrm{~cm}$, estrigoso, inserido acima da base da ócrea. Racemos densifloros 8-10cm. Flores ca. $2 \mathrm{~mm}$. Fruto oval, 5-8mm, lobos aderidos.

A espécie é distribuída principalmente na mata atlântica, nos estados de Santa Catarina, São Paulo, Rio de Janeiro, Pará, Bahia e Minas Gerais (Howard 1992). No domínio do semiárido ocorre na mata de cipó, transição entre a mata atlântica e caatinga, nos municípios de Vitória da Conquista e Morro do Chapéu.

\section{Material selecionado:}

Bahia: Morro do Chapéu, 15/V/1973, F. B. Ramalho 1238 (MG, RB); Vitória da Conquista, 04/III/1978, S. Mori et al. 9413 (K); Idem, 19/II/1992, A. M. de Carvalho 3796 (HUEFS).

\section{Polygonum L., Gen. Pl. 5:170, 1754.}

Ervas ou subarbustos, caule prostrado radicante, ramos ascendentes até $1,5 \mathrm{~m}$ alt.; glabros ou pubescentes. Folhas membranáceas, lanceoladas, glabras ou pubescentes, margem inteira, ciliada, glândulas punctiformes freqüentes; ócrea cilíndrica, membranácea, margem estrigosa; pecíolo inserido na ócrea. Inflorescência racemosa bi ou tri-ramificada. Flores diminutas envoltas por bráctea membranácea cônica (ocréola). Perianto 4-5 partido, indistinto; androceu 5-8 estames; gineceu bi ou tricarpelar, estilete bi 
ou tri-partido, estigma globóide ou capitado; glândulas nectaríferas presentes. Fruto diclésio, encoberto pelo perianto marcescente.

As espécies do gênero Polygonum ocorrem na zona semi-árida do estado da
Bahia, invariavelmente nas margens dos rios, lagos e lagoas. P. hispidum e P. ferrugineum são as espécies mais freqüentes. $P$. acuminatum, $P$. hydropiperoides e $P$. punctatum são pouco coletadas até o presente.

\section{CHAVE PARA IDENTIFICAÇÃO DAS ESPÉCIES DO GÊNERO POLYGONUM}

1 Fruto lenticular

2 Planta híspido-pubescente, ócrea com margem revoluta, foliácea 3. P. hispidum

2' Planta glabra ou pubescente, ócrea com margem truncada, membranácea

3 Planta glabra ou com tricomas lanuginosos quando jovens, ócrea ferruginosa, margem glabra 2. P. ferrugineum

3' Planta pubescente ao menos nas nervuras foliares e pedúnculos, margem da ócrea estrigosa 1. P. acuminatum

1 'Fruto trígono

4 Perianto frutífero com glândulas punctiformes 5. P. punctatum

4' Perianto frutífero sem glândulas punctiformes 4. P. hydropiperoides

\section{Polygonum acuminatum Kunth, Nov.} Gen. et Sp. Pl. 2:178, 1817.

(Fig. 26-27)

Erva até $1,5 \mathrm{~m}$ alt., ramos estrigosos. Folhas lanceoladas, 8-15 x 1,5-3cm, ápice agudo longo-atenuado, base arredondada ou obtusa, tomentosas, raro glabras; ócrea 1$3,5 \mathrm{~cm}$, pubescente, raro glabra, margem estrigosa; pecíolo até $1 \mathrm{~cm}$. Racemos densifloros, pedúnculos pubescentes; ocréolas cônico-afuniladas, margem ciliada. Flor 3-4mm, glândulas nectaríferas bem desenvolvidas. Fruto lenticular, faces convexas, 2-3mm, perianto acrescente após a frutificação.

Ocorre nas regiões Sul, Sudeste, Centrooeste e Nordeste brasileiras (Melo 1991). Espécie pouco coletada no semi-árido do estado da Bahia. Ocorre em populações ao longo das margens dos rios e locais inundáveis na região semi-árida do estado da Bahia.

\section{Material selecionado:}

Bahia: Ibotirama, 06/VI/1996, F. França et al. 1657 (HUEFS); Lençóis, Remanso/ Marimbus, 29/I/1997, B. Stannard et al. PCD 4646 (ALCB, HUEFS, SPF).
2. Polygonum ferrugineum Wedd., Ann. Sc. Nat. Ser. 3, 13:252, 1849.

(Fig. 28-29)

Erva até $1 \mathrm{~m}$ alt.; ramos glabros. Folhas lanceoladas a oval-lanceoladas, 10-20 x 3$4,5 \mathrm{~cm}$, ápice longo-acuminado, base decurrente até $2 / 3$ do pecíolo, lanuginosopubescentes a glabras, viscosas, glândulas punctiformes marrom-amareladas em ambas as faces; ócrea $1-3 \mathrm{~cm}$, glabra ferruginosa, margem truncada, glabra, marcescente; pecíolo 0,5-1cm. Racemos densifloros, pedúnculos glabros, ocréolas cônicas, margem estrigosa. Flor 3-4mm, glândulas nectaríferas pouco desenvolvidas. Fruto lenticular, 2,5-4mm, faces ligeiramente côncavas, perianto frutífero não acrescente.

É encontrada nos estados do Paraná, Goiás, Mato Grosso do Sul, Distrito Federal, Bahia, Ceará, Pará e Amazonas (Melo 1991). Ocorre ao longo das margens de rios, lagoas e áreas inundáveis na região do semi-árido baiano.

\section{Material selecionado:}

Bahia: Anguera, F. França et al. 1642 (HUEFS); Bom Jesus da Lapa, 29/I/1970, P. 
Carauta 1034 (RB); Cachoeira, Barragem Pedra do Cavalo, IV/1980, Scardino et al. 3 (ALCB, HRB); Ibotirama, 06/VI/1996, F. França et al. 1659 (HUEFS); Jequié, 26/VIII/ 1964, C. M. M. 247 (CEPEC); São Felipe, 22/ II/1956, R. P. Lordêlo 203 (HRB); Serrinha, 05/VII/1951, O. Travassos 47 (RB).

\section{Polygonum hispidum Kunth, Nov. Gen. Sp. Pl. 2:178, 1817.}

(Fig. 30-31)

Erva até $1 \mathrm{~m}$ de alt.; ramos estrigosopubescentes. Folhas oval-lanceoladas, 12-20 x $4-8 \mathrm{~cm}$, ápice atenuado, base decurrente, estrigosas, glândulas punctiformes em ambas as faces; ócrea foliácea, margem franjada, revoluta, $2 \mathrm{~cm}$, híspido-pubescente; pecíolo $2 \mathrm{~cm}$, estrigoso. Racemos densifloros, pedúnculos estrigosos, ocréolas cônicas, pubescentes. Flor $3-4 \mathrm{~mm}$, perianto com glândulas esparsas, glândulas nectaríferas desenvolvidas. Fruto lenticular, $2-4 \mathrm{~mm}$, faces côncavas, perianto frutífero não acrescente.

Ocorre no Ceará, Piauí, Pernambuco e Minas Gerais (Cialdella 1989). Espécie muito comum no semi-árido baiano, às margens de lagoas e locais inundáveis.

\section{Material selecionado:}

Bahia: Anguera, F. França et al. 1644 (HUEFS); Feira de Santana, Serra São José, 8/VII/1982, J. Arauck et al. 192 (HRB); Idem, 8/VII/1982, K. B. Britto 020 (HRB); Iaçu, 26/ II/1983, G. C. P. Pinto 164 (HRB); Idem, IV/ 1974, G. C. P. Pinto 42296 (ALCB, IPA); Ipirá, 23/VI/1995, E. Melo et al. 1298 (HUEFS); Itaju do Colônia, 18/I/1971, T. S. dos Santos 1333 (CEPEC); Itiúba, 25/V/83, G. C. Pinto \& H. P. Bautista 97/83 (RB, HRB); Jacobina, 4/VII/1996, R.M. Harley et al. PCD 3388 (ALCB, HUEFS, SPF); Joazeiro, 16/VII/1978, I. Pontual 78-1646 (PEUFR); Jussiape, 26/III/ 1977, R. M. Harley et al. 20022 (CEPEC, HRB, MBM); Livramento do Brumado, 02/II/ 1988, R. M. Harley et al. 25864 (CEPEC, MBM); Manoel Vitorino, 20/XI/1978, S. A. Mori et al. 11230 (CEPEC); Serra Preta, 17/ 07/85, L. R. Noblick \& Lemos 4129 (CEPEC);
Uauá 30/VII/1984, H. P. Bautista \& R. P. Orlandi 962 (HRB, MBM); Vitória da Conquista, 17/I/1965, E. Pereira \& G. Pabst 9503 (R).

\section{Polygonum hydropiperoides Michx., Fl. Bor. Amer. 1:239, 1803.}

Erva até $40 \mathrm{~cm}$ alt.; ramos glabros. Folhas estreito-lanceoladas 5-9 x 0,8-1,2cm, ápice e base atenuados, margens e nervuras ciliadas, face abaxial freqüentemente com glândulas opacas; ócrea 1-1,5cm, margem ciliada, pecíolo curto, 2-5mm. Racemos $6-7 \mathrm{~cm}$, pedúnculos glabros, ocréolas cônicas de margem ciliada. Flor 2-3mm, glândulas nectaríferas pouco desenvolvidas. Fruto trígono $1-2 \mathrm{~mm}$, liso e brilhante, perianto frutífero sem glândulas, não acrescente.

Espécie bem distribuída nas regiões Sul, Sudeste, Centro-oeste do Brasil (Melo 1991). $\mathrm{Na}$ área de estudo foi pouco coletada até o presente.

\section{Material selecionado:}

Bahia: Itaberaba, 04/VI/1995, F. França et al. 1225 (HUEFS); Morro do Chapéu, 27/ VI/1996, R. M. Harley et al. PCD 3108 (ALCB, HUEFS); Idem, 4/III/1997, E. N. Lughadha et al. PCD 6017 (SPF).

\section{Polygonum punctatum Ell., Sketch. Bot. D. Carol. Geogr. 1:455, 1817.}

(Fig. 32-33)

Erva até $50 \mathrm{~cm}$ alt.; ramos glabros. Folhas lanceoladas a oval-lanceoladas 6-12 x 1,5-4cm, ápice atenuado, base aguda, glabras, glândulas punctiformes em ambas as faces, margens ciliadas; ócrea 1-1,5cm, margem ciliada; pecíolo 1-1,5cm. Racemos 6-11 cm, pedúnculos glabros, ocréolas cônicas, afuniladas. Flor 2$3 \mathrm{~mm}$, perianto com glândulas punctiformes, glândulas nectaríferas pouco desenvolvidas. Fruto 1,5-2mm, trígono, liso e brilhante, perianto frutífero punctato-glanduloso, não acrescente.

No Brasil encontra-se distribuída nos estados do Pará, Maranhão, Bahia, Distrito Federal, Goiás, Mato Grosso, Mato Grosso do 
Sul, Rio de Janeiro, Minas Gerais, São Paulo, Rio Grande do Sul, Paraná e Santa Catarina (Melo 1991). Na área estudada é pouco coletada até o momento.

\section{Material selecionado:}

Bahia: Caatiba/Barra do Choça, 15/III/ 1979, S. A. Mori \& T. S. dos Santos 11549 (CEPEC); Jussiape, 26/III/77, R. M. Harley 20027 (CEPEC, HRB, MBM); Morro do Chapéu, 4/III/1997, E. N. Lughadha et al. PCD 6013 (ALCB, HUEFS, SPF).

Rumex L. Syst. 1:357, 1735.

\section{Rumex crispus L., Sp. Pl. 1:335, 1753.}

Erva ereta pouco ramificada, até $1,5 \mathrm{~m}$ alt. Folhas oblongo-lanceoladas, membranáceas, glabras, margem inteira, ondulada, as basais mais desenvolvidas, $20-30 \times 5-8 \mathrm{~cm}$, ápice agudo, base obtusa; folhas reduzidas ao longo dos eixos florais; ócrea 3-6cm, membranácea, glabra, marcescente; pecíolo $5-10 \mathrm{~cm}$. Racemos frequientemente bi ou tri-ramificados, fascículos de flores espaçados. Perianto 1$2 \mathrm{~mm}, 3$ peças internas maiores que as externas; androceu 3 estames, anteras basifixas; gineceu com estigmas multifidos. Fruto diclésio, 5-8mm, alas livres, com calo dorsal desenvolvido e margens lisas.

Espécie citada pela primeira vez para o estado da Bahia.

\section{Material examinado:}

Bahia: Rui Barbosa, 27/IV/97, R.M. Harley \& A.M. Giuletti (HUEFS).

\section{Ruprechtia C. A. Meyer, Mém. Acad. Imper. St. Pétersb. 6:148, 1848.}

Árvore ou arbusto até 20m alt., dióicos. Folhas elípticas, oblongas a lanceoladas, coriáceas a submembranáceas; margem inteira a ondulada; nervação broquidódroma; glabras ou pubescentes; ócrea caduca; pecíolo achatado dorsalmente. Racemos múltiplos, subpaniculados, flores masculinas com 6 pétalas; androceu com 9 estames ligados na base; flores femininas com 3 pétalas atrofiadas. Fruto pseudosâmara, perianto frutífero ligado na base até $1 / 3$, encobrindo parcial ou totalmente o fruto, glabro a densamente pubescente externamente, alas acrescentes.

\section{CHAVE PARA IDENTIFICAÇÃO DAS ESPÉCIES DO GÊNERO RUPRECHTIA}

1 Folhas pubescentes em ambas as faces 3. $R$. ramiflora

1' Folhas glabras

2 Tubo do perianto frutífero inexistente, glabro, alas livres até a base expondo o fruto 2. R. laxiflora

2 ' Tubo do perianto frutífero aberto acima de $2 / 3$ do fruto, pubescente externamente 1. R. apetala

1. Ruprechtia apetala Wedd., Ann. Sci. Nat. Sér. 3. 13:268, 1849.

Árvore ou arbusto de 3,5-8m de alt.; ramos com casca acinzentada, enegrecida, lenticelas punctiformes, alvas, esparsas. Folhas elípticas a oblongas, 4,5-12 x 2,5-7,5cm, coriácea a submembranácea; ápice obtuso a arredondado, raramente subacuminado; base aguda, obtusa ou arredondada, margem ondulada; face adaxial com nervação impressa, pubescência esparsa, raro totalmente glabra, face abaxial com nervação proeminente, pubescência alva, densa; ócrea caduca; pecíolo 0,3-1 cm. Racemos múltiplos, subpaniculados, densifloros, raque densamente pubescente. Flores masculinas $1-2 \mathrm{~mm}$, flores femininas com pétalas reduzidas, filiformes, $6 \mathrm{~mm}$. Perianto frutificado $2-3 \mathrm{~cm}$, tubo $7 \mathrm{~mm}$, aberto acima de $2 / 3$, externamente estrigoso, alas espatuladas, 2-2,6 x 5-8mm, esparsamente pubescentes. Pericarpo tricostado, liso. 
Ocorre em todo o nordeste do Brasil. Espécie muito comum ao longo das margens dos rios, na região semi-árida do estado da Bahia.

\section{Material selecionado:}

Bahia: Aracatu, 27/III/1984, C. B. de A. Bohrer 10 (ALCB, HRB, HUEFS); Baraúna, 28/VII/1981, G. M. Barroso s. n (IBGE); Boa Nova, 3/IV/1984, L. C. Oliveira Filho \& J. C. A. Lima 146 (HRB, HUEFS, MBM); Boquira, 20/III/1984, H. P. Bautista \& O. A. Salgado 852, 855 (ALCB, HRB, HUEFS, IPA, MBM, RB, UPCB); Brumado, 26/III/1984, J. A. C. Lima \& L. C. de Oliveira Filho 81 (ALCB, CEPEC, HRB); Idem, 03/VII/1983, L. Coradin et al. 6371 (CEN); Curaçá/Terra Nova, 1983, G. C. Pinto \& S. B. da Silva 201/83 (ALCB, HRB, HUEFS, MBM); Camaçari, Área da Caraíba Metais, 17/III/1966, A. A .Castelhanos 25827 (MBM); Irecê, 17/II/1981, M. S. G. Ferreira 140 (IBGE); Joazeiro, 26/II/1962, A. L. Costa 1039 (ALCB); Idem, 24/I/1993, W. Thomas et al. 9638 (CEPEC); Livramento do Brumado, 25/V/1991, A. J. Ribeiro 268 (ALCB); Idem, 12/III/1991, H. S. Brito \& G. P. Lewis 290 (CEPEC); Manuel Vitorino, 1984, G. C. Pinto, 57, 70 (ALCB, HRB, HUEFS); Idem, 16/II/1979, L. A. Mattos Silva et al.282 (CEPEC); Idem, 22/II/1973, T. S. dos Santos 2587 (CEPEC); Paramirim, 13/III/1981, S. B. da Silva 199 (CEPEC, HUEFS, UB).

\section{Ruprechtia laxiflora Meisn., in: Mart., Fl. Bras. 5(1):56, 1855.}

Árvore até $20 \mathrm{~m}$ de alt.; ramos com casca acinzentada, enegrecida, lenticelas arredondadas. Folhas elípticas a lanceoladas, lâmina 3-6 x 1,5-3cm, coriácea, ápice obtuso a arredondado, raramente subacuminado; base aguda, obtusa ou arredondada, margem ondulada; face adaxial com nervação impressa, glabrescente, face abaxial com nervação proeminente, pubescência alva, esparsa; ócrea caduca; pecíolo $0,3-1 \mathrm{~cm}$, achatado dorsalmente. Racemos múltiplos, subpaniculados, densifloros, raque densamente pubescente. Flores masculinas 1-2mm, flores femininas com pétalas reduzidas, filiformes, $6 \mathrm{~mm}$. Perianto frutificado $2-3 \mathrm{~cm}$, aberto até quase a base, externamente pubescente, alas espatuladas, 2-2,6 x 5-8mm, esparsamente pubescente. Pericarpo tricostado, 3-5mm, pubescência restrita ao $1 / 3$ anterior das costas.

Ocorre na Bahia e Minas Gerais (Meisner 1856). Muito freqüente nas bordas das matas semidecíduas da zona semi-árida do estado da Bahia.

\section{Material selecionado:}

Bahia: Almadina, 12/III/1971, R. S. Pinto 1137 (CEPEC); Bonfim de Feira, 14/V/1984, L. R. Noblick et al. 078, 079 (ALCB, HUEFS); Castro Alves, II/1981, Scardino et al. 1012, 1087 (ALCB, HRB, HUEFS); Idem, 1956, R. Lordêlo s.n. (ALCB); Feira de Santana, 19/II/1981, A. M. Carvalho et al. 588 (CEPEC); Idem, 28/I/1993, L. P. Queiroz et al. 3068 (CEPEC, HUEFS); Itaju do Colônia, 23/X/1969, T. S. dos Santos 429 e 431 (CEPEC, HRB, HUEFS, RB); Idem, 23/X/ 1969, T. S. dos Santos 431 (HRB); Itiúba, 21/ II/1974, R. M. Harley 16469 (IPA); Olindina, 20/VII/1993, O. B. Borges 35 (HRB, RB); Rui Barbosa, 12/IV/1986, H. P. Bautista \& A. C. Sarmento 1107 (HRB, MBM, RB); Senhor do Bonfim, 25/V/1974, D. Andrade-Lima s. n. 747654 (IPA); Serra Preta, 17/VII/1985, L. R. Noblick \& Lemos 4152 (ALCB, HRB); Jeremoabo/Paulo Afonso, 14/V/1981, H. P. Bautista 450 (CEPEC, HRB, IPA, RB); Idem, 8/IV/1993, M. C. Ferreira 502 (HRB).

\section{Ruprechtia ramiflora (Jacq.) Meyer,} Mém. Acad. St. Petersb. ser.6:150, 1840.

(Fig. 34-38)

Árvore 3-8m alt.; ramos cinza-escuro, lenticelas inconspícuas. Folhas elípticas, 3-7 x $2-4,5 \mathrm{~cm}$, verde-acinzentadas, densamente pubescentes em ambas as faces, margem plana a ligeiramente ondulada, diminuto-ciliada, coriáceas, nervação marcada em ambas as faces; pecíolo 2-3mm, pubescente. Flores masculinas $2-3 \mathrm{~mm}$, Flores femininas $1 \mathrm{~cm}$, sépalas 3, externamente pubescente, pétalas 
3, reduzidas, glabras; gineceu trígono-alongado, estigmas alongados, papilosos; Perianto frutífero $2,5-3,5 \mathrm{~cm}$, tubo $7 \mathrm{~mm}$, aberto acima do $2 / 3$ do fruto, alas espatuladas. Pericarpo trígono-sulcado, liso.

Habita as regiões xerofíticas da costa e zonas do norte da América do Sul (Cocucci 1961). Na zona semi-árida estudada, ocorre nas margens do Rio São Francisco.

Material selecionado:

Bahia: Barra, 26/II/97, L. P. de Queiroz 4863, 4866 (HUEFS); Idem, 24/II/97, L. P. de Queiroz 4830 (HUEFS).

Triplaris Löefl. ex L. Gen. Pl.:256, 1758

1. Triplaris gardneriana Wedd., Ann. Sci. Nat. III. 13:265, 1849.

(Fig. 39-43)

Árvore 4-15m alt.; dióica; ramos glabros, estriados, casca marrom, enegrecidas, lenticelas elípticas a arredondadas, alvas, esparsas. Folhas oval-lanceoladas a elípticas, 9-14 x 3-5cm, ápice agudo, base arredondada freqüentemente assimétrica, margem plana, raramente ondulada, coriácea, face adaxial glabra a esparsamente pubescente, face abaxial pubescente, nervação marcada nas duas faces; ócrea caduca; pecíolo 1-1,5cm, achatado, glabrescente. Inflorescências paniculiformes, densifloras; brácteas 1-1,5mm, densamente tomentosas, bractéolas $3-5 \mathrm{~mm}$, estrigosas externamente. Perianto 3-5mm, basalmente conato por $2-3,5 \mathrm{~mm}$, tubo pubescentes externamente; estames 6-9, exsertos. Flores femininas com brácteas de $5-10 \mathrm{~mm}$, tomentosas externamente, tubo do perianto oval a campanulado $0,5-1 \mathrm{~cm}$, externamente pubescente; pétalas lineares, reduzidas, 1$1,5 \mathrm{~cm}$, glabras; perianto frutificado $2,5-4,5 \mathrm{~cm}$, alas espatuladas. Pericarpo trígono-ovalado, $1 \mathrm{~cm}$, liso.

Ocorre no Ceará (Meisner 1856). Na zona semi-árida é frequiente nas bordas de rios e nas planícies fluviais.

\section{Material selecionado:}

Bahia: Bom Jesus da Lapa, 18/VI/1986,
G. Hatschbach \& J. M. Silva 50483 (CEPEC, UPCB); Idem, 10/VI/1992, A. M. de Carvalho et al. 3973, 3975 (CEPEC); Campo Formoso, 05/IX/1961, R. P. Orlandi 521 (ALCB, CEPEC, HRB); Curaçá, 19/VIII/1983, S. B. da Silva \& G. C. P. Pinto 266 (ALCB, CEPEC, HRB); Idem, 10/VIII/1983, G. C. P. Pinto \& S. B. da Silva 198/83 (CEPEC, HRB); Joazeiro, 07/IX/1971, A. L. Costa (ALCB); Palmas do Monte Alto, 01/VI/1984, M. M. Santos 94 (ALCB, CEPEC, HRB, IPA); Porto Nacional, 27/VII/1951, A. L. Costa (ALCB); Xique-Xique, 22/VI/1996, M. L. Guedes et al. PCD 2946 (ALCB, HUEFS).

\section{AGRADECIMENTOS}

Aos Diretores de Herbários que permitiram o acesso às coleções botânicas e, especialmente àqueles que contribuíram com a doação, empréstimo de material e fotografias de tipos. À Universidade Estadual de Feira de Santana pelo financiamento parcial deste trabalho.

\section{REFERÊNCIAS BIBLIOGRÁFICAS}

Aiouad, M. S. 1986. Clima da caatinga. In: Simpósio sobre caatinga e sua exploração racional. Embrapa/ Universidade Estadual de Feira de Santana. Feira de Santana, Bahia, p.3748.

Bautista, H. P. 1986. Espécies arbóreas da caatinga: sua importância econômica. In Simpósio sobre a caatinga e sua exploração racional. Embrapa/ Universidade Estadual de Feira de Santana. Feira de Santana. Bahia, p.117140.

Centro De Estatística E Informações (CEI). 1994. Informações básicas dos Municípios baianos. Salvador. 14 volumes.

Cialdella, A. M. 1989. Revision de las especies argentinas de Polygonum s.1. 
(Polygonaceae). Darwiniana 29(1-4): 179-246.

Cocucci, A. E. 1961. Revision del genero Ruprechtia (Polygonaceae). Kurtziana 1:217-269.

Harley, R. M. \& Mayo, S. 1980. Towards a checklist of the flora of Bahia. Kew: Royal Botanic Garden, 250 p.

Harley, R. M. \& Simmons, N. A . 1986. Florula de Mucugê, Chapada Diamantina, Bahia, Brazil. Kew: Royal Botanic Garden, 228 p.

Harley, R. M. 1995. In: Stannard, B. L. (Ed.). Flora of the Pico das Almas, Chapada Diamantina - Bahia, Brasil. Kew: Royal Botanic Garden. 853p.

Heywood, V. H. 1978. Flowering plants of the world. London: Oxford University Press. 335 p.

Holmgren, P. K., Holmgren, N. H. \& Barnett, L. C. 1990. Index Herbariorum, part. I. The Herbaria of the world. 8a.ed. New York: New York Botanical Garden. $693 \mathrm{p}$.

Howard, R. A. 1960. Studies in the genus Coccoloba, IX. A critique of the south american species. Journ. Arn. Arb. 41: 213-258 e 357-390.

1992. Collected notes on Coccoloba (Polygonaceae). Brittonia 44: 356-367.

Meisner, C. F. 1856. Polygonaceae. In: Martius, C. Flora Brasiliensis, v. 5, n.1 p.1-59.

Melo, E. 1991. O gênero Polygonum L. (Polygonaceae) no Estado do Paraná, Brasil. Dissertação de Mestrado. Curitiba: Universidade Federal do Paraná, $126 \mathrm{p}$. . 1996. O gênero Polygonum L (Polygonaceae) no estado da Bahia, Brasil. Sitientibus 14: 45-55.

Noblick, L. R. 1991. The indigenous palms of the state of Bahia, Brazil. Tese de Doutorado. Chicago: University of Illinois.

Rizzini, C. M. 1978. Revisão monográfica do gênero Coccoloba no Brasil - I. espécies da restinga. Rodriguesia 30: 127-161. 1986. Contribuição ao estudo do gênero Coccoloba (Polygonaceae). Espécies campestres. Dissertação de Mestrado. Rio de Janeiro: Universidade Federal do Rio de Janeiro, $116 \mathrm{p}$.

Spjut, R. W. 1994. A systematic treatment of fruit Types. Mem. N.Y. Bot. Gard. 70: 1-182.

Veloso, H. P., Rangel Filho, A. L., Lima, J. C. 1991. Classificação da vegetação brasileira, adaptada a um sistema Universal. Rio de Janeiro: IBGE, Departamento de Recursos Naturais e Estudos Ambientais. 124 p. 


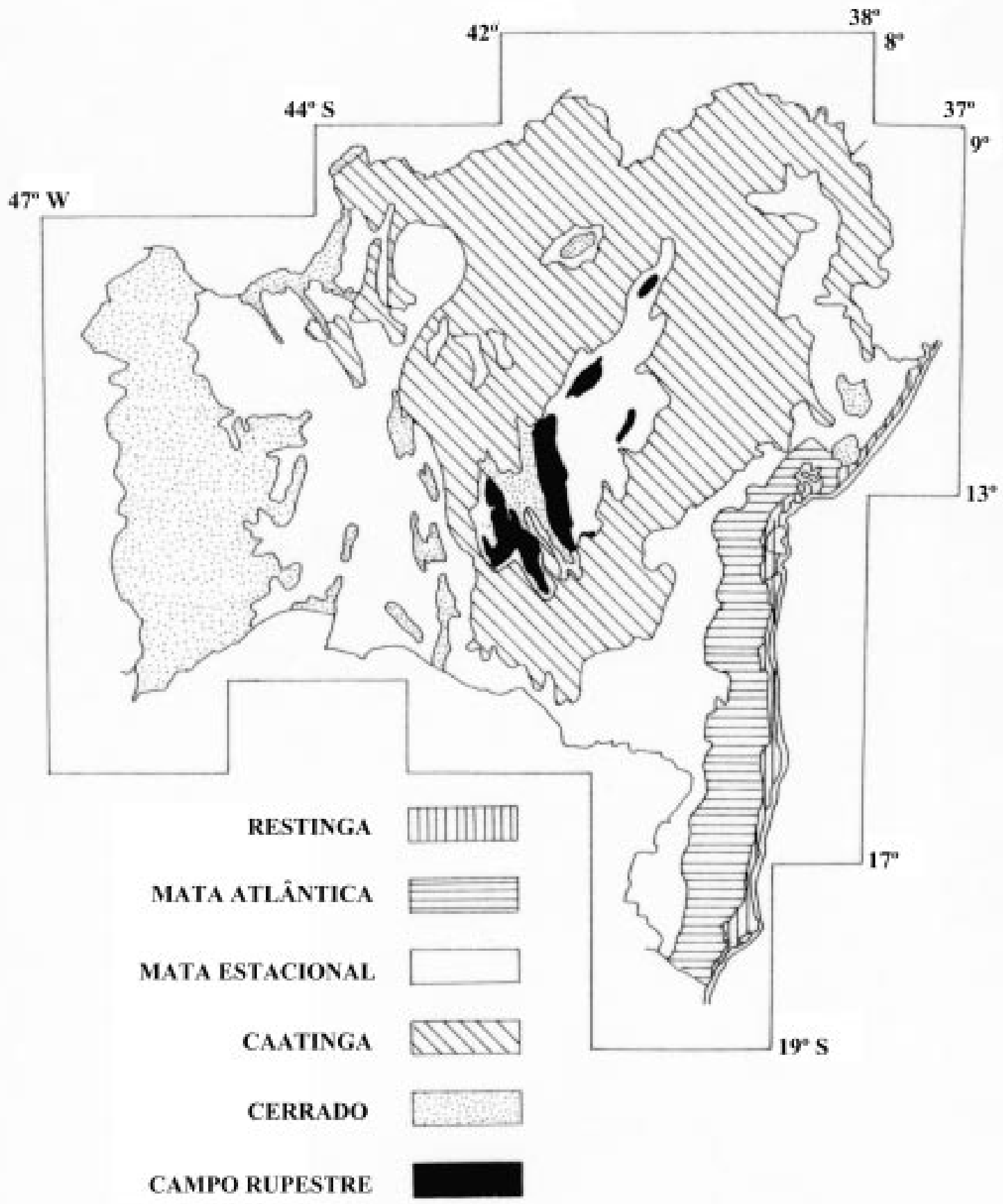

Figura 1 - Mapa de distribuição da vegetação no estado da Bahia (NOBLICK, 1991) 


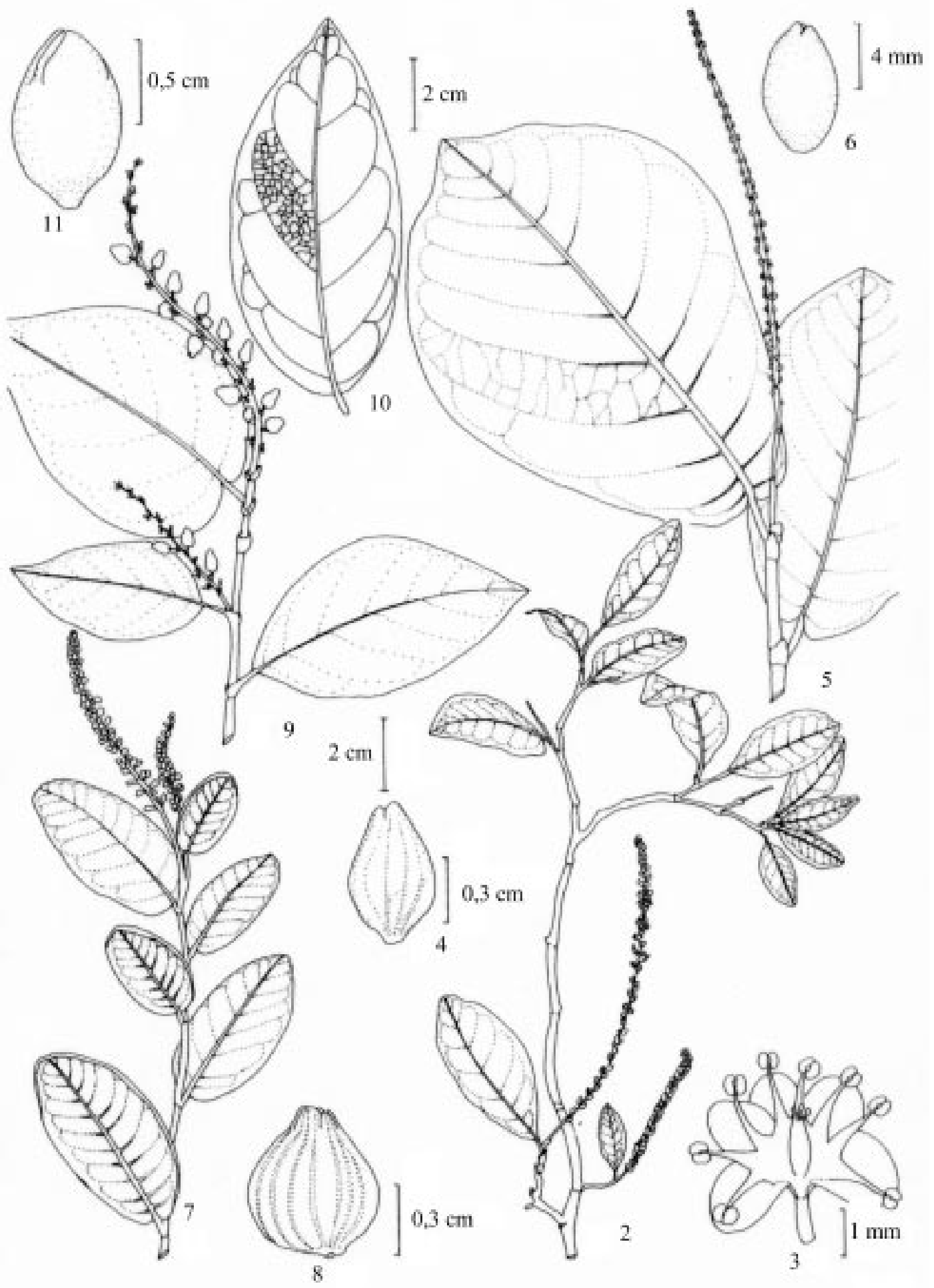

Figuras 2-11 - Coccoloba. 2-4. C. alagoensis, 2 - hábito, 3 - flor, 4 - fruto (L. P. de Queiroz 4847); 5-6. C. alnifolia, 5 hábito, 6 - fruto; 7-8. C - brasiliensis, 7 - hábito, 8 - fruto (E. Melo \& F. França 1233); 9-11. C. confusa, 9 - hábito, 10 - folha, 11 - fruto (L. P. de Queiroz 3046). 


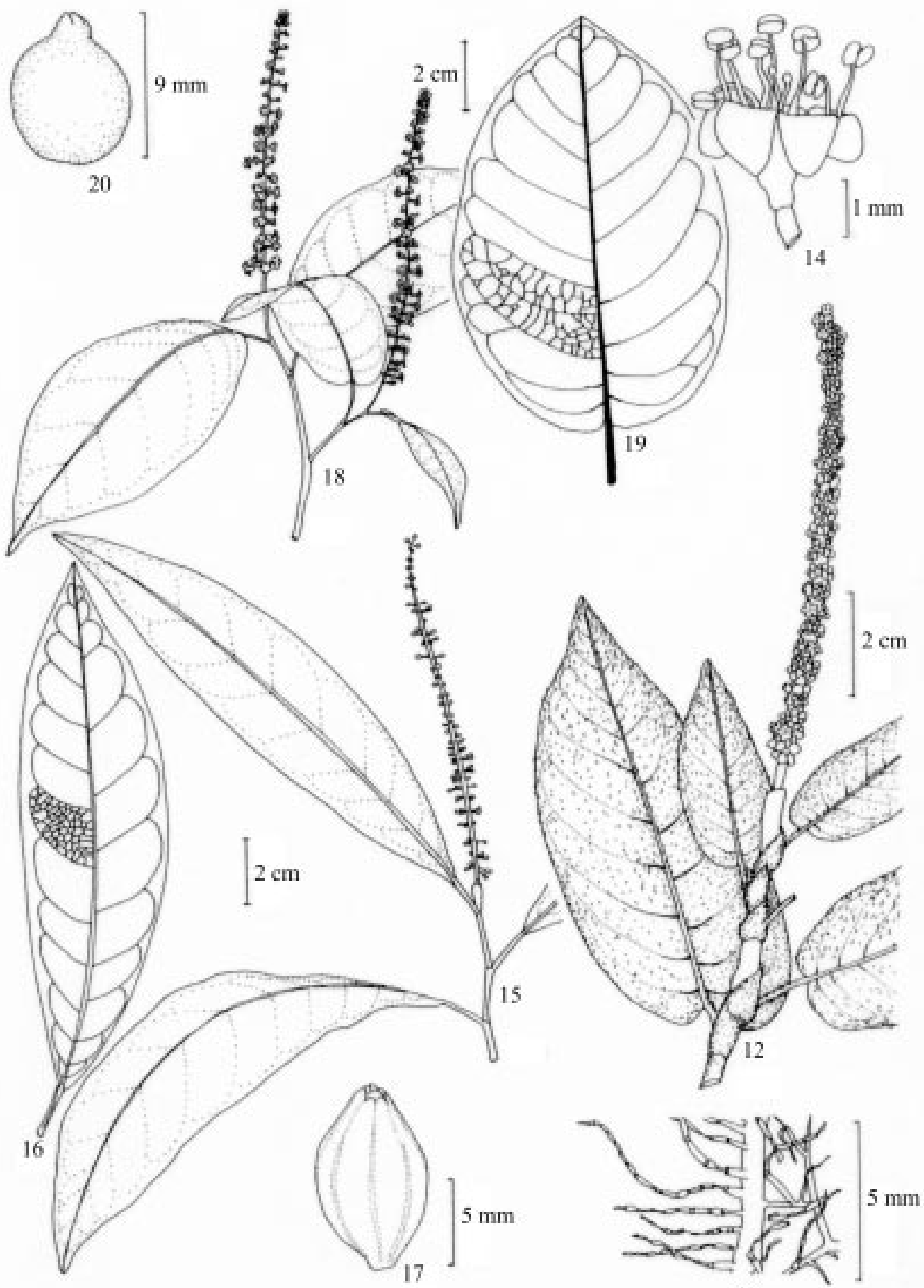

13

Figuras 12-19 - Coccoloba. 12-14. C. fastigiata, 12 - hábito, 13 - detalhe da folha, 14 - flor (G. Hatschbach 46566); 1517. C. mosenii, 15 - hábito, 16 - folha, 17- fruto (F. França et al. 2098); 18-20. C. ochreolata, 18 - hábito, 19-folha, 20 - fruto (F. França et al. 1086). 


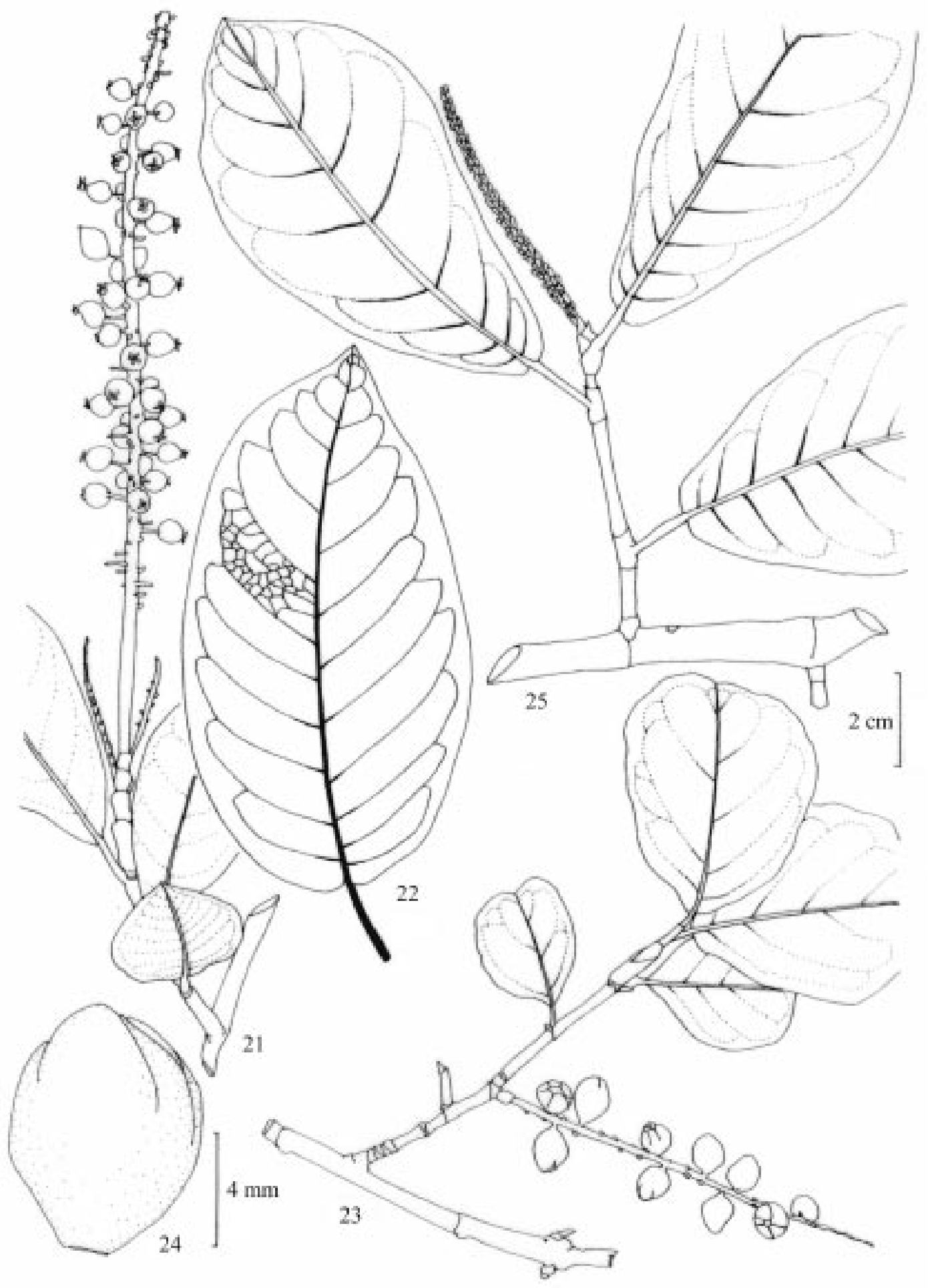

Figuras 21-25 - Coccoloba. 21-22. C. scandens, 21 - hábito, 22 - folha (E. Melo et al. 1700); 23-24. C. schwackeana, 23 - hábito, 24 - fruto (E. Melo et al. 1639); 25. C. warmingii, 25 - hábito (A . M. de Carvalho 3796). 


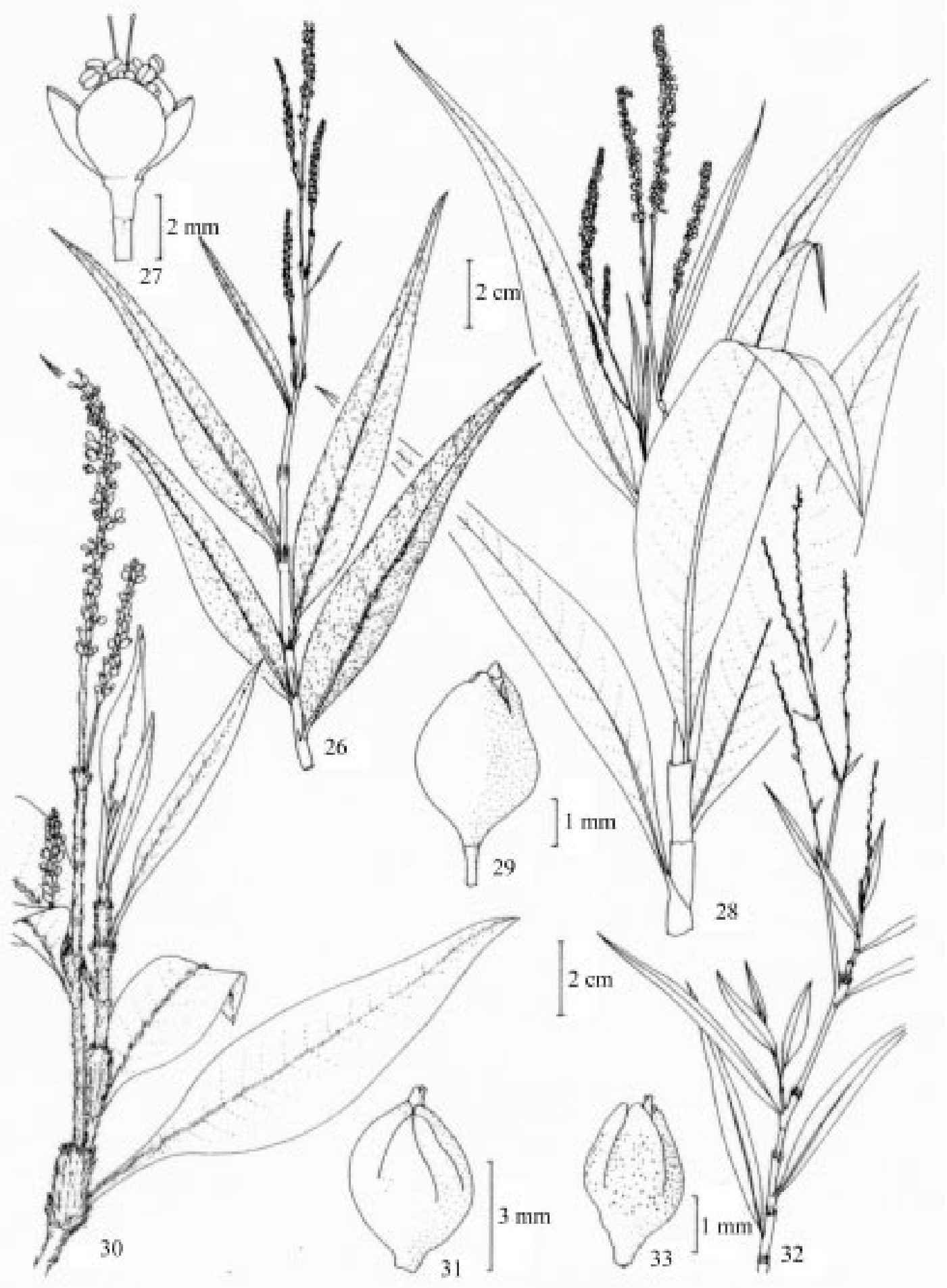

Figuras 26-33 - Polygonum. 26-27. P. acuminatum, 26 - hábito, 27 - flor (F. França et al. 1657); 28-29. P. ferrugineum, 28 - hábito, 29 - fruto (F. França et al. 1642); 30-31. P. hispidum, 30 - hábito, 31 - fruto (F. França et al. 1644); 32-33.P. punctatum, 32 - hábito, 33 - fruto (E. N. Ludghadha et al. 6013). 


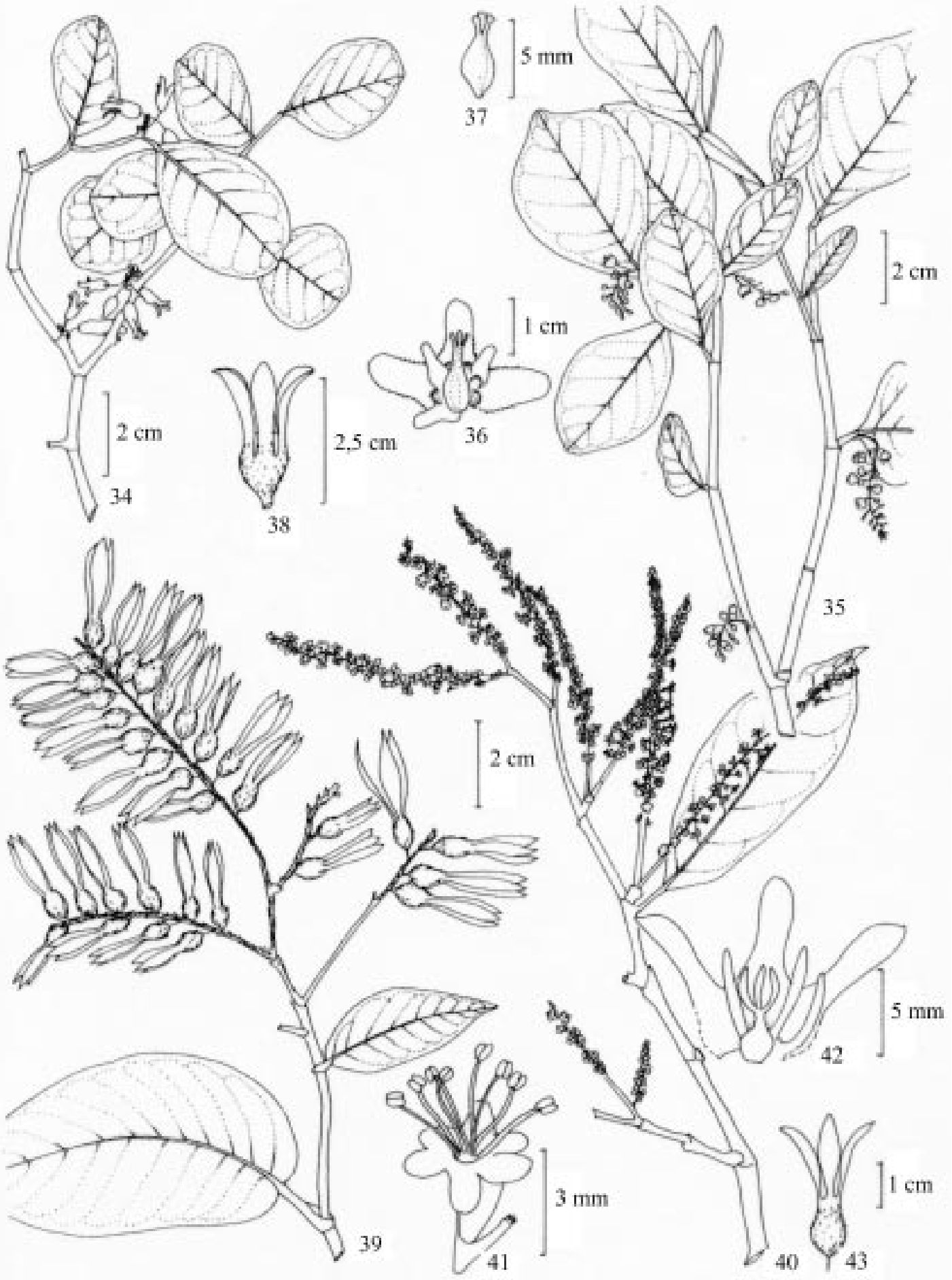

Figuras 34-43 - Ruprechtia. 34-38 - R. ramiflora. 34 - hábito, planta feminina, 35 - hábito, planta masculina, 36 - flor pistilada, 37 - gineceu isolado, 38 - fruto (L. P. de Queiroz 4863 e 4866); 39-43. Triplaris gardneriana Wedd. 39 - hábito, planta feminina, 40 - hábito, planta masculina, 41 - flor estaminada, 42 - flor pistilada, 43 - fruto (G. Hatschbach \& J. M. Silva 50483). 
